\title{
Research on the Teaching Reform Methods of College Students' Mental Health Education from the Perspective of New Media
}

\author{
Yifan Wang \\ Baoshan University, Baoshan Yunnan 678000 China
}

Keywords: new media; mental health education; teaching reform methods.

\begin{abstract}
Colleges and universities are the bases that cultivate talents, which train students' learning skills on the basis of emphasizing the promotion of students' professional knowledge and launch the corresponding scientific mental health education combining with their real demands. So the corresponding talent training model can be rationally optimized. This paper will focus on the teaching reform methods of college students' mental health education from the perspective of new media. It clarifies the positive impact of mental health education based on the learning status of current college students and claims to promote rational education guidelines and system and offer more valuable reference for teachers' teaching through the more effective methods.
\end{abstract}

\section{Introduction}

Along with the gradual manifestation of Internet application value, college teaching claims to rationally use its advantages to deeply influence students' mental growth and development. The teaching reform methods of college students' mental health education from the perspective of new media actively cater to students' practical demands and pay attention to their real needs as well as the reasonable handling and solution with every problem. The application value of new media emergence is of great significant to the college education teaching. Only fully combining with current college students' characteristics and launching the rational psychological counseling can better environment be created and students grow up in a more harmonious space.

\section{Advantages of Mental Health Education from the Perspective of New Media}

\subsection{Strengthen the Mental Health Education}

Mental health education is of great significance to students, and they should accept regular psychological counseling no matter which stage they are in. Only by this way can the value of mental health education be given full play to. New information platform requires college teachers to understand basic application skills to better use such kind of technology and create more rational topics for students. The quantity of college students is very large. So the result will be even more dangerous if students cannot get effective help after having mental problems, and it will even damage students' physical and mental health. Thus, colleges should pay attention to the effective combination of environment and mental health education under the new media. Besides, they help students relieve psychological anger and confusion through the careful analysis with the application value of new media technology and gradually broadening the platform of mental health to make students get instant solutions to mental problems through the method of searching in the Internet so that the dangerous degree can be reduced to the lowest.

\subsection{Keep Secret with Students' Mental Condition}

New media technology is equipped with the confidentiality, which can keep secret with students' mental condition after the overall analysis. It can cater to those shy students who will instantly appear the anxious and nervous sense even lose their heads and be ashamed to tell their own situation to others after they find the mental problems. Part of students worry that their mental problems will be seen by others, so they hope that their negative emotions can be poured out through the Internet, a more secret method to share with the online psychologists. Such method can help them more positively confirm their own problems and timely find out scientific methods to solve the mental problems. 


\section{The Effect of New Media on the College Mental Health Education}

College students afford various pressures, so there will exist those sad emotions that cannot be released and the mental security danger will be certainly formed. Due to the emergence of new media, college students' mental health education can be timely implemented and their minds can get scientific guidance and release at the same time of relieving their pressures.

\subsection{The Material Demand is Satisfied While the Inner Mind Is Empty}

College students can obtain rather wide information and data every day by means of mobile phone and Internet, especially APP and self-media, which make college students' cognition and behavior have obvious change. The appearance of new media broadens college students' vision. And currently, information communication is more active, so college students achieve the communication and exchange with outside and satisfy their yearnings for the life out of school. The gradual development of new media has realized the effective exchange with different information and data, which makes student complete various detailed work via the Internet. Also, they will be affected by different negative news while obtaining the related information and data during the spreading process of new media information. These effects prevent students from the right attitude for living and cognition. Although college students can release their emotions by means of new media technology, they will fine the abnormal fickleness after the completion of emotion expression.

\subsection{Students are More Likely to Express Thoughts by Means of the Media Technology}

The gradual development of new media has made students have more diversified methods to sense themselves, and their social perception will gradually enhance. Students will form the cognition with society and their outlooks during the period of university. And they still have not establish rather scientific information handling model when collecting related information, so they are not equipped with good control demands. So the related managing operation models will usually have rather heavy negative impacts on college students. College students have been accustomed to such communication method by means of the speciality of new media so that they are unwilling to communicate with people face to face. So there exists the incomplete and imperfect communication structure and there also exists the difference on the emotion expression. Besides, those technological geeks have lost the ability to communicate with people and they are so addicted to the Internet that they cannot gain the satisfaction from getting along with people. As time passes, they will have rather heavy mental problems.

\subsection{Students Enhance the Cognition with Society by Means of New Media Technology.}

Nowadays, the new media technology is rapidly developing, college students usually make the information spreading through Internet media platform. And this kind of frequency will increase along with the update of society. New media has been the exploration method of students' mental demands. In order to better express the era characteristics, current college students bravely express their own opinions and thoughts on the new media platform so as to avoid mental conflict and provide powerful basis for parents and teachers' guidance and teaching. Students's mental condition can be timely known through the popularization of new media, teachers, parents and counselors. The related reports show that modern young people are much more dependent on mobile phones so that they suffer from "cell phone anxiety" that means they will repeatedly open the phone within one hour. This will result in that part of students who have rather low discipline put too much effort into the new media.

\section{Teaching Reform Methods of College Students' Mental Health Education from the Perspective of New Media}

\subsection{Promote the Life Education in Time}

Currently, life education has its own special connotation, and only the steady improvement can enhance people's cognition and feeling with life and give full play t the reality of life education. Socalled life education is not the ultimate dream above the life and it also cannot better perfect the shortcomings of life. The combination of life education and life can manifest the ultimate meaning and value of life. This is the basic process of current colleges gradually promoting the life education. 
So the existence of key point needs to be focused on. In the specific teaching activity, teachers should not be shy when discussing the death, and they can advocate students face the value of life through the method of group mental counseling, topic application or case discussion. Then students will eliminate the negative cognition with life in the exploration process and be encouraged to deeply reflect and feel the value of life in the process of listening and communication. Teachers should fully realize the concept of people oriented when constructing the mental education course. They should accurately judge students' mental appeal point though the scientific analysis with teaching mechanism and structure, which can better reduce the bad effect of new media on college students. As for current college students, only by steadily improving the learning quality and cognition can they train their own mental endurance and guarantee better construct complete character quality.

\subsection{College Sex Education Should Promote the Strength and Coverage}

As for college education, sex education is an essential content and the corresponding strength and coverage should be strengthened when necessary.

\subsubsection{Change Teaching Contents and Methods}

Sex education is an essential content in the college education system, which needs to focus on the plural channels to avoid the isolated understanding and imagining to have a wrong guidance on students. They should pay attention to the implementation of sex education and encourage students to establish correct concepts. When teachers are steadily improving their comprehensive qualities, the school should offer great support and fully absorb teaching models of different levels. College counselors play the important role, and they should achieve the primary judgement with students' mental problems so as to avoid heavy effects. Sex education cannot purely rely on the isolated teaching model but focus on the teaching frame and rational interaction among teaching mechanisms and the positive promotion of teachers' learning abilities. Properly update the speed combining with the dynamic of knowledge, deeply implement and explore more effective leaning mechanisms and train teachers' comprehensive teaching levels.Affected by the new media, college teachers can advocate students positively use their phones to obtain more diversified information, for instance, the adoption of turning class to hold on the lading role of task and pay attention to the prominence of students' body value and launch rational mental health education. Besides, they should promote students' understanding degree on mental cognition and construct more scientific operation structure aiming at the basic conditions to guarantee students to understand the theory knowledge of sex education and timely get rid of students' mistakes in the cognition structure from the more comprehensive basis.

\subsubsection{Change the Concept on Sex in Time}

Timely update on the concept of sex is of great significance to college students. In the changing today, the principle of equality between men and women has been gradually advocated, and masculinity and femininity have obviously been replaced by the model created by the differentiated gender. People's concept on marriage and love have changed under the influence of traditional concepts, also making obvious change on the power relation and autonomy. The update of era has affected the traditional binary so that every teacher is supposed to positively realize the effective promotion of practical quality and establish more scientific cognition and train the communication ability.

\subsection{Properly Update the Concept About Love}

Make real-time update of the emotion and concept between the sexes with by means of more diversified methods. This requires every teacher to establish balanced concept of love and spread it to students with scientific method and encourage them correctly treat the meaning of the lovelorn. For students, teachers are the leaders in the way of study. So the percentage of appearing the mental barrier will be reduced through the effective psychological service for students. In the process of launching mental health education, teacher should comprehensively analyze students' practical appeal. For instance, they are supposed to help students better accept their own same sex realization and make rational mental health instruction for them. 


\subsection{Rationally Update Sexual Morality}

The concept of human's sexual morality has not been unified in the practical development, so it mainly regards the value as the significant moral standard. However, it is in the process that the open concept is allowed to guarantee the manifestation of sexual morality under the human power theory. Properly respect science and not make moral kidnapping even the moral judgment. Teachers are more likely to launch the guidance through traditional static mental teaching method and establish the new teaching model integrated with the virtual and actual. They get together and research the rational dynamic operation mechanism in order to strengthen the communication efficiency between students and teachers.

\section{Conclusion}

Affected by the new media, the teaching reform methods of college students' mental health education should launch proper exploration. And teachers should fully analyze students' real needs to construct more scientific teaching plan and education system and choose more appropriate teaching methods. They can focus on students' basic demands and construct more complete education system and extract more practical teaching plan combining with multiple education models to guarantee the efforts of students' strengthening mental health and help teachers better give full play to the teaching value. The connection of new media and students can achieve the effective interaction and help them better express their advantages to ensure the positive impact of new media fully manifested. Besides, they can encourage students better participate in the communication to promote the teaching effects of mental health.

\section{References}

[1]. Yanxia Guo. Teaching Reform of College Students' Mental Health Education Based on the New Media[J]. Occupation, 2016(06):116-117.

[2]. Ying Ma. The Significant Effect of Mental Health on the College Mental and Political Education[J]. Research on Urban Construction Theory(electronic edition),2017(34):207-208.

[3]. Jun Zhang, Bin Zhang. Analysis of Chinese College Students' Mental Health Education Model in the era of New Media[J]. Journal of Chifeng college(Science edition), 2017,33(21):96-97.

[4]. Xueqin Chen, Yudi Wang. Discussion on the College Students' Work Innovation under the New Media — Taking the example of Nanjing Sports Institute[J]. Policy,2017,15(18):240-241+243.

[5]. Lizheng Wu. Discussion on the Mental Health Education Model Integrated Online to Offline by the Higher Vocational Colleges in the era of "Internet + " $[\mathrm{J}]$. Higher Vocational Education(Journal of Tianjin Vocational University),2017,26(03):49-54.

[6]. Lu Chen, Fengmiao Li, Li Zhang, Yurou Zhang, Yuanyuan Zheng. College Students' Network Quality Survey and SWOT Analysis under the Era of New Media[J]. Exam Week, 2015(A3):110+156.

[7]. Jingjing Yang. Thinking on College Students' Mental Health Education Work from the Perspective of New Media[A]. College Students' Psychological Counseling Professional Committee of Chinese Mental Health Association. Chinese special College students' mental health education - the twelfth national college students' mental health education and counseling academic exchange proceedings[C]. College Students' Psychological Counseling Professional Committee of Chinese Mental Health Association:,2015:4.

[8]. Yuan Zhang. Several Thoughts on the Positive Impact of College Mental and Political Education Work on College Students' Innovation and Entrepreneurship[J]. Good Parent, 2016(29):247. 